\title{
Effects of continuous infusion of phenylephrine vs. norepinephrine on parturients and fetuses under LiDCOrapid monitoring: a randomized, double-blind, placebo-controlled study
}

Kunpeng Feng ${ }^{1,2}$, Xiaohua Wang ${ }^{1,2}$, Xuexin Feng ${ }^{1,2}$, Jinfeng Zhang ${ }^{3}$, Wei Xiao ${ }^{1,2}$, Fengying Wang ${ }^{4}$, Qi Zhou ${ }^{4}$ and Tianlong Wang ${ }^{1,2^{*}}$ (I)

\begin{abstract}
Background: Hypotension following spinal anesthesia (SA) during cesarean delivery (CD) occurs commonly and is related with maternal and fetal complications. Norepinephrine infusion is increasingly used for prevention of postSA hypotension; however, its effects as compared to the traditional phenylephrine infusion remain unclear. This study aimed to compare the effects of phenylephrine and norepinephrine administered as continuous infusion during elective CD on maternal hemodynamic parameters and maternal and fetal outcomes.
\end{abstract}

Methods: This prospective, single-center, randomized, controlled study included 238 consecutive term parturients who underwent CD from February 2019 to October 2019. They were randomized to receive continuous infusion of $0.25 \mu \mathrm{g} / \mathrm{kg} / \mathrm{min}$ phenylephrine, $0.05 \mu \mathrm{g} / \mathrm{kg} / \mathrm{min}$ norepinephrine, or placebo. Hemodynamic monitoring was performed at 10 time points using LiDCOrapid. We analyzed umbilical vein (UV), umbilical artery (UA), and peripheral vein (PV) blood gas indexes and recorded intraoperative complications.

Results: In phenylephrine group, the systolic blood pressure (SBP) remain during the whole operation. Compared to the control group, phenylephrine, but not norepinephrine, significantly increased the systemic vascular resistance (SVR) to counteract the SA-induced vasodilatation, 3 min following norepinephrine/phenylephrine/LR administration (T4): $957.4 \pm$ 590.3 vs $590.1 \pm 273.7(P<0.000001) ; 5$ min following norepinephrine/phenylephrine/LR administration (T5): $1104 \pm 468.0$ vs $789.4 \pm 376.2(P=0.000002)$. at the time of incision (T6): $1084 \pm 524.8$ vs $825.2 \pm 428.6(P=0.000188)$. Parturients in the phenylephrine group had significantly lower UV $(1.91 \pm 0.43)(P=0.0003)$ and UA $(2.05 \pm 0.61)(P=0.0038)$ lactate level compared to controls. Moreover, the UV pH value was higher in the phenylephrine than in the control group7.37 \pm $0.03(P=0.0013)$. Parturients had lower incidence of nausea, tachycardia, hypotension in phenylephrine group.

(Continued on next page)

\footnotetext{
* Correspondence: w_t15595@hotmail.com

'Department of Anesthesiology, Xuanwu Hospital, Capital Medical University, Beijing 100053, China

${ }^{2}$ National Clinical Research Center for Geriatric Disorders, Beijing 100053,

China

Full list of author information is available at the end of the article
}

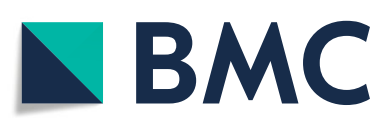

(c) The Author(s). 2020 Open Access This article is licensed under a Creative Commons Attribution 4.0 International License, which permits use, sharing, adaptation, distribution and reproduction in any medium or format, as long as you give appropriate credit to the original author(s) and the source, provide a link to the Creative Commons licence, and indicate if changes were made. The images or other third party material in this article are included in the article's Creative Commons licence, unless indicated otherwise in a credit line to the material. If material is not included in the article's Creative Commons licence and your intended use is not permitted by statutory regulation or exceeds the permitted use, you will need to obtain permission directly from the copyright holder. To view a copy of this licence, visit http://creativecommons.org/licenses/by/4.0/ The Creative Commons Public Domain Dedication waiver (http://creativecommons.org/publicdomain/zero/1.0/) applies to the data made available in this article, unless otherwise stated in a credit line to the data. 
(Continued from previous page)

Conclusions: In this dataset, continuous phenylephrine infusion reduced the incidence of SA-induced hypotension, ameliorated SVR, while decreasing overall maternal complications. Phenylephrine infusions are considered the better choice during CD because of the significant benefit to the fetus.

Trial registration: Clinicaltrial.gov Registry, NCT03833895, Registered on 1 February 2019.

Keywords: Cesarean delivery, In-term parturient, LiDCOrapid system, Norepinephrine, Phenylephrine, Spinal anesthesia

\section{Background}

Spinal anesthesia (SA) is the standard and preferred mode of care for elective cesarean delivery (CD) [1], but SA can negatively affect the parturient or the fetus by reducing the placental perfusion [2]. SA-induced maternal hemodynamic fluctuations during $\mathrm{CD}$ can invoke nausea and vomiting, cardiovascular collapse, massive hemorrhage, unconsciousness with resulting pulmonary aspiration, or, in extreme cases, cardiorespiratory arrest $[3,4]$. According to recent studies, SA-induced hypotension occurs in $80 \%$ of all parturients and nearly $60 \%$ of in-term parturients during $C D$ without prophylactic use of vasopressors due to sympathetic blockade by the anesthesia [5, 6]. Thus, obstetric anesthetists increasingly opt for prophylactic vasopressor use for routine prevention of post-SA hypotension during $\mathrm{CD}$ [7]. In recent years, the optimization of hemodynamics, particularly post-SA hypotension during $\mathrm{CD}$, remains the critical management challenge for anesthesiologists.

Phenylephrine, an $\alpha$-adrenergic agonist and a vasopressor of choice in obstetric anesthesia, is sometimes associated with maternal cardiac depression or reflex bradycardia. This cardiac depressant effect limits its use in parturients with cardiac comorbidities. Norepinephrine, a potent $\alpha$ adrenergic agonist with weak $\beta$-adrenergic agonistic activity, is associated with a lower incidence of maternal bradycardia. Thus, recently, norepinephrine is considered a potential vasopressor of choice during $\mathrm{CD}$ at a maintenance dose of $0.05 \mu \mathrm{g} / \mathrm{kg} / \mathrm{min}$ [8]. These pharmacologic properties make norepinephrine and phenylephrine attractive choices as vasopressors in CD. However, new evidence points to post-SA hypotension reversal by phenylephrine without significant maternal bradycardia [9]. In addition, prophylactic use of phenylephrine at $0.25 \mu \mathrm{g} / \mathrm{kg} / \mathrm{min}$ results in better neonatal outcomes and reduced maternal mortality [10]. The choice for phenylephrine has been reported to be more beneficial for parturients $[11,12]$ Nonetheless, comparative studies of these two drugs for continuous infusion are limited, and evidence on the optimum vasopressor choice is lacking.

Therefore, this study aimed to compare the effects of phenylephrine and norepinephrine administered as continuous infusion during elective $C D$ on 1) maternal hemodynamic parameters using noninvasive LiDCOrapid $^{\mathrm{mix}}$; and 2) maternal and fetal outcomes based on umbilical vein (UV), umbilical artery (UA), and maternal peripheral vein (PV) blood gas indexes.

\section{Methods}

\section{Ethical considerations}

This study was approved by the Capital Medical University Institutional Review Board on January 23, 2019 (IRB \# 2019-058). Written informed consent was obtained from all participants. The study was registered at ClinicalTrials. gov (http://clinicaltrials.gov; NCT-03833895) on February 1, 2019. Participant recruitment was performed from February 2019 to October 2019. Our methodology followed the international guidelines for randomized clinical studies according CONSORT Guidelines.

\section{Study design and participants}

This was a prospective, single- center, randomized, controlled clinical study conducted from February 2019 to October 2019 in the Xuanwu Hospital, Beijing, China. Parturient meeting the following inclusion criteria were recruited: 1) healthy singleton pregnancy; 2) scheduled elective CD under combined spinal-epidural anesthesia (CSEA); 3) American Society of Anesthesiologists physical status I/II; and 4) age between 20 and 45 years. The exclusion criteria were as follows: 1) history of mental disorder, epilepsy, or other central nervous system disease; 2) tricyclic or imipramine antidepressant use; 3) preexisting or pregnancyinduced hypertension; 4) lumbar injury; 5) severe hypovolemia; 6) allergy or history of hypersensitivity to vasopressors; 7) body mass index $>40 \mathrm{~kg} / \mathrm{m}^{2}$; and 8) infection at the puncture site.

\section{Randomization and blinding}

Randomization was performed using computergenerated randomized numbers and allocation concealment was ensured using sequentially numbered opaque sealed envelopes. An anesthesiologist not involved in parturient care was responsible for opening the envelopes and preparing the study medicine.

The study medicine and sealed wrapping instructions were delivered to the operating room before the time of $\mathrm{CD}$. The study medicine was prepared in $50 \mathrm{~mL}$ syringes containing phenylephrine, norepinephrine, or placebo, marked with a randomization number. The dose of each medicine was calculated according to the participant's standard weight, defined as the actual height minus 110 $\mathrm{cm}$ [13], and then the medicine was diluted to $50 \mathrm{~mL}$ at different concentrations. The three groups were infused 
in the same speed at $20 \mathrm{ml} / \mathrm{h}$. Anesthesiologists involved in infusion of the medicine or parturient care were blinded to the group allocation. Randomization codes were not revealed to the blinded anesthesiologists until all measurements and calculations had been entered into the database and statistical methods had been specified.

\section{Anesthesia protocol}

On arrival in the operating room, standard monitoring was initiated, including noninvasive blood pressure (BP) measurement, heart rate (HR) measurement, pulse oximetry, and electrocardiography. Patients were asked to rest still for $5 \mathrm{~min}$. Subsequently, hemodynamic parameters were measured thrice at 2-min intervals, and the mean value was considered the baseline. Next, venous access was established using a 16-gauge intravenous (IV) cannula and $10 \mathrm{~mL} / \mathrm{kg}$ lactated Ringer's solution (LR) was infused in all groups before CSEA.

CSEA was performed with the patient in the right lateral position using $0.5 \%$ bupivacaine $(7.5 \mathrm{mg}, 1.5 \mathrm{~mL}$, isobaric, $1.0 \mathrm{~mL} / 10 \mathrm{~s}$ ) injected into the subarachnoid space at the L2-L3 interspace. An epidural catheter was inserted cephalad for a rescue SA. Immediately after anesthesia induction, patients were placed in the supine position with $15^{\circ}$ left lateral tilt. The sensory block level before surgical incision was T4.

Intraoperatively, maintenance LR $(3 \mathrm{ml} / \mathrm{kg} / \mathrm{h})$ was provided for all groups according to the parturients' standard weight. Additionally, parturients received a continuous infusion of the study drug according to the group allocation. After delivery of the fetus, a bolus of 5 IU oxytocin was administered IV followed by a slow infusion of another $5 \mathrm{IU}$ over the remainder of the operation in all three groups.

\section{Interventions}

In the phenylephrine group, parturients received a continuous infusion of phenylephrine at the rate of $0.25 \mu \mathrm{g} /$ $\mathrm{kg} / \mathrm{min}$ according to their standard weight [14]. In the norepinephrine group, parturients received a continuous infusion of norepinephrine at the rate of $0.05 \mu \mathrm{g} / \mathrm{kg} / \mathrm{min}$ according to their standard weight [8]. In the control group, parturients received a continuous infusion of LR as the same speed.

Hypotension was defined if the systolic BP (SBP) reduced by $30 \%$ relative to the baseline value or an absolute $\mathrm{SB} P$ value of $<100 \mathrm{mmHg}$. The time interval for BP measurement was set at $3 \mathrm{~min}$. The shortest interval for vasopressor administration was every $1 \mathrm{~min}$. In case of severe hypotension (SBP reduced by more than 30\% relative to the baseline value), additional bolus of vasopressor was given; $25 \mu \mathrm{g}$ of phenylephrine in the phenylephrine group or $4 \mu \mathrm{g}$ of norepinephrine in the norepinephrine group. In the control group, additional bolus of $4 \mu \mathrm{g}$ norepinephrine was administered in case of hypotension combined with a HR $>60 \mathrm{bpm}$ and additional bolus of $25 \mu \mathrm{g}$ phenylephrine was administered in case of hypotension combined with a HR $<60 \mathrm{bpm}$. In this study, $0.5 \mathrm{mg}$ atropine was administered continually for 3 min only in case of simple bradycardia (HR $<50$ bpm). The vasopressor infusion was stopped if the SBP increased to > $150 \mathrm{mmHg}$ for over $3 \mathrm{~min}$.

\section{Outcome measurement}

LiDCOrapid Pulse Contour Analysis System (LiDCO Ltd., London, UK) was used in all three groups to measure the hemodynamic parameters at each time point. The hemodynamic parameters included stroke volume (SV), cardiac output (CO), systemic vascular resistance (SVR), SBP, diastolic blood pressure (DBP), mean arterial pressure (MAP), and HR. All parameters were measured at baseline (T1), at the time of spinal injection (T2), at placement in supine position (T3), 3 min following norepinephrine/phenylephrine/LR administration (T4), $5 \mathrm{~min}$ following norepinephrine/phenylephrine/LR administration (T5), at the time of incision (T6), immediately after fetus delivery (T7), at the time of placental expulsion (T8), 5 min after placental expulsion (T9), and at discharge to the postoperative unit (T10).

Blood samples were taken from the UA, UV, and PV for analysis by the blood gas analyzer (Radiometer ABL800 FLEX analyzer, Radiometer A/S, Copenhagen, Denmark) immediately after delivery. The measured parameters included oxygen partial pressure $\left(\mathrm{PO}_{2}\right)$, oxygen saturation $\left(\mathrm{SO}_{2}\right)$, carbon dioxide partial pressure $\left(\mathrm{PCO}_{2}\right)$, glucose and lactate levels, base excess $(\mathrm{BE}), \mathrm{pH}$, and anion gap (AG). Intraoperative fluid input and output were recorded. The postoperative incidence of maternal complications, such as hypotension, tachycardia, bradycardia, nausea and vomiting, breathing difficulty, and dizziness was also recorded.

The primary outcome of the study was the SBP as important one of hemodynamic parameters in each group at different time point. The secondary outcomes included hemodynamic parameters (DBP, MAP, HR, SV, $\mathrm{CO}, \mathrm{SVR})$, the blood gas indices $\left(\mathrm{PO}_{2}, \mathrm{SO}_{2}, \mathrm{PCO}_{2}, \mathrm{BE}\right.$, $\mathrm{pH}, \mathrm{AG}$ ) in UV, UA, and PV blood samples, and the incidence of complications.

\section{Sample size calculation}

In our pilot study $(n=20)$, the increase of systolic blood pressure (SBP) in the norepinephrine and phenylephrine compare with control groups were $\Delta 31 \mathrm{mmHg}$ and $\Delta 20$ mmHg respectively. Using PASS 15.0, a sample size of 71 in the phenylephrine group and 70 in the norepinephrine group was required for $\alpha$ (Type I error) of 0.05 and $\beta$ (Type II error) of 0.2 . Considering a $10 \%$ withdrawal rate, the sample size was calculated at 79 per group. 


\section{Statistical analysis}

Statistical analyses were performed using SPSS (version 22.0, SPSS Inc., Chicago, IL, USA). Categorical data were expressed as number of episodes/participants counts and compared among the three groups by the Chi-squared test. Intergroup comparisons of the mean values of parameters and the mean variations using the Tukey Kramer multiple comparison test. In the time-series data in each group was determined using one-way repeated measures ANOVA during the whole operation. All data were analyzed by the Shapiro-Wilk test for normality of distribution. Normally distributed quantitative variables were presented as means \pm standard deviation. A $P$ value of $<0.05$ was considered statistically significant.

\section{Results}

\section{Demographic data}

Of the 266 recruited parturients, 28 were excluded, 238 were included in the study, and 235 successfully completed the study (Fig. 1). The parturient' s demographics (age, weight, height, BMI) and baseline of the parameter (SBP, DBP, MAP, HR, CO, SV, SVR) were similar in all three groups (Table 1). The median sensory block height at skin incision reached T4 in all three groups. The urine output, amount of blood loss, and the total volume of infusion were also similar in all groups. There was no significant difference in the duration of delivery, anesthesia, and operation, and the APGAR score among the three groups (Table 2).

\section{Hemodynamic parameters}

In Phenylephrine group, the SBP and MAP higher than control group at T4,5 timepoints. DBP In Phenylephrine group were significantly higher than control group at T3,4,5,6 timepoints. HR In Phenylephrine group were significantly lower than control group at T3,4,5,6,7,8 timepoints, and also lower than Norepinephrine group at T5,6,7,8,9 timepoints (Supplement-table-1) (Fig 2a). SVR in Phenylephrine Group significantly were higher than Control group at T4,5,6 timepoints. T4: $957.4 \pm$ 590.3 vs $590.1 \pm 273.7(P<0.000001)$; T5: $1104 \pm 468.0$ vs $789.4 \pm 376.2(P=0.000002)$. T6: $1084 \pm 524.8$ vs $825.2 \pm$ $428.6(P=0.000188)$ (Fig 2b).

In Norepinephrine group, SBP and MAP were higher than control group at T4,5 timepoints. DBP were higher than control group at T3,4 timepoints (Supplement-table1) (Fig 2a). SVR in Norepinephrine Group was significantly higher than Control group at $\mathrm{T} 4$ timepoints. T4: $865.0 \pm 360.1$ vs $590.1 \pm \pm 273.7(P=0.000043)$ (Fig. $2 b)$.

We also proceed inter-group comparison to reflect the variation trend in each group. In control group, compare with baseline, the SBP was significantly decreased at T3, T4, T5, T6, T7 (Supplement-table-1). The DBP was significantly decreased at T4, and the MAP was significantly decreased at T4, T5. In control group, compare with $\mathrm{T} 1$ (baseline), the $\mathrm{CO}$ was significantly increased at $\mathrm{T} 9$, the SV was significantly increased at T7, T8 timepoint, and the SVR was significantly decreased at T3, T4,T7, T8,T9,T10 timepoint (Fig. 2b) (Supplement-table-1). In norepinephrine group, compare with T1(baseline), the SBP was slightly decreased at T6, the DBP was significantly decreased at T10 timepoint, the MAP was slightly decreased at T10 and the HR was slightly decreased at T4, T5, T6 timepoint (Supplement-table-1). (Fig. 2a). In phenylephrine group, compare with T1 timepoint (baseline), the HR was slightly decreased

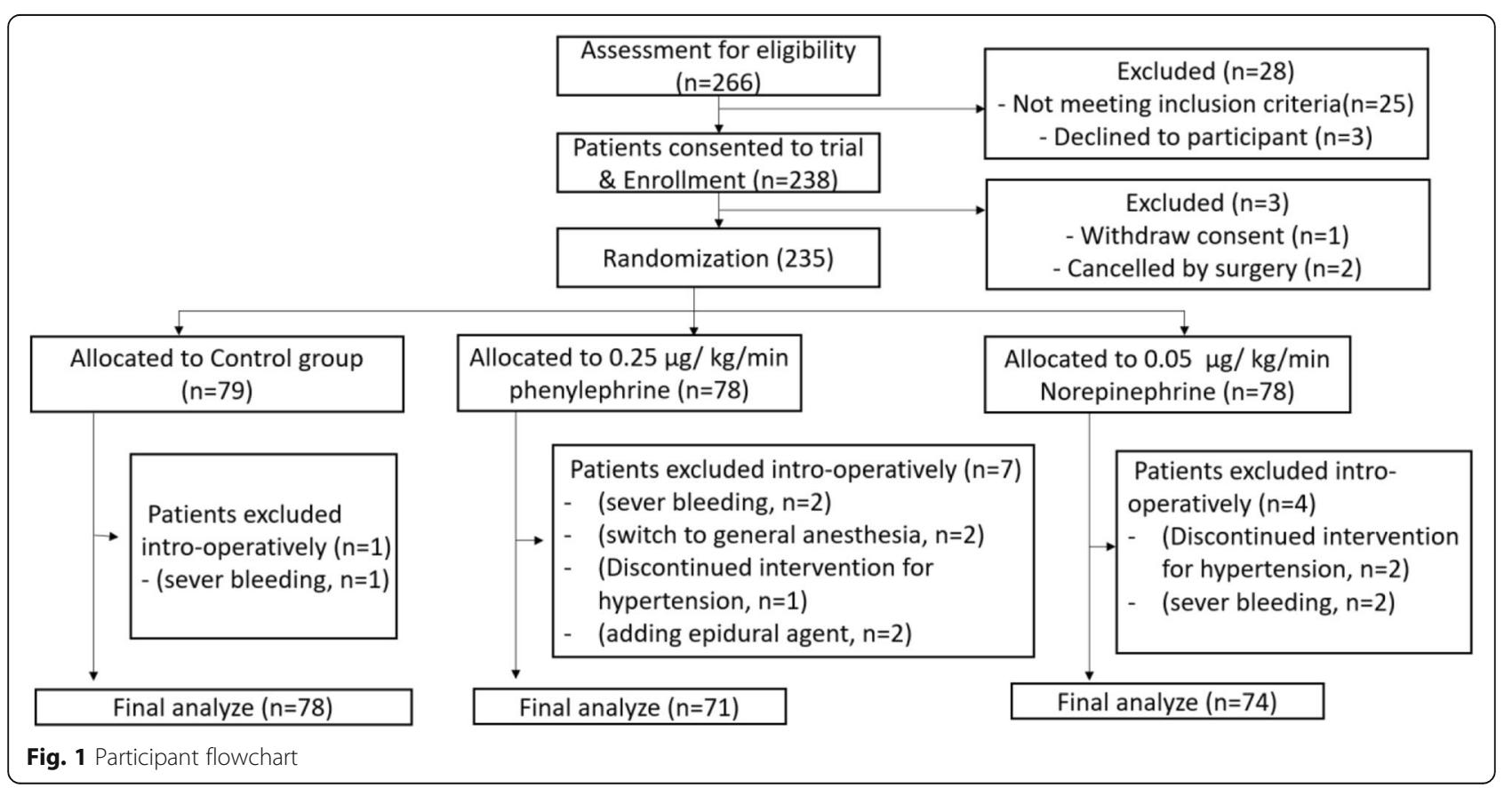


Table 1 Parturient demographics and baseline characteristics of the phenylephrine, norepinephrine and control group

\begin{tabular}{|c|c|c|c|c|c|}
\hline Variables & Control group $(n=78)$ & Phenylephrine group $(n=71)$ & Norepinephrine group $(n=74)$ & F value & $P$ value \\
\hline Age, years & $34.04(4.80)$ & $33.34(3.77)$ & $33.70(4.26)$ & 0.4904 & 0.6130 \\
\hline Weight, kg & $77.77(12.28)$ & $75.36(8.43)$ & $76.09(11.41)$ & 0.9642 & 0.3829 \\
\hline Height, cm & $162.41(5.72)$ & $161.704 .27(4.27)$ & $161.77(5.46)$ & 0.4253 & 0.6541 \\
\hline $\mathrm{BMI}, \mathrm{kg} / \mathrm{m}^{2}$ & $29.49(4.52)$ & $28.79(2.59)$ & $29.06(3.92)$ & 0.6635 & 0.5161 \\
\hline Baseline $\mathrm{CO}, \mathrm{L} / \mathrm{min}$ & $8.42(2.46)$ & $7.87(2.58)$ & $8.43(2.53)$ & 1.182 & 0.3087 \\
\hline Baseline SVR, dyn $\mathrm{s} \mathrm{m}^{2} / \mathrm{cm}^{5}$ & $968.37(344.23)$ & $968.37(269.26)$ & $971.17(340.18)$ & 0.045 & 0.9561 \\
\hline Baseline SV, ml & $95.83(25.14)$ & $91.26(26.87)$ & $93.85(24.46)$ & 0.6079 & 0.5454 \\
\hline Baseline SBP, mmHg & $120.19(11.72)$ & $117.14(9.66)$ & $120.64(12.38)$ & 2.054 & 0.1306 \\
\hline Baseline DBP, mmHg & $68.44(13.04)$ & $66.49(9.79)$ & $69.54(11.98)$ & 1.245 & 0.2901 \\
\hline Baseline MAP, mmHg & $81.28(15.81)$ & $78.68(11.31)$ & $81.59(18.59)$ & 0.7657 & 0.4662 \\
\hline Baseline Heart rate, beats/min & $87.38(12.81)$ & $87.41(11.57)$ & $91.16(10.54)$ & 2.797 & 0.0631 \\
\hline
\end{tabular}

BMI Body Mass Index, Data are expressed as mean (SD); SD Standard deviation. ${ }^{*} 0.25 \mu \mathrm{g} / \mathrm{kg} / \mathrm{min}$ phenylephrine vs. control group, $P<0.05 ; \# 0.05 \mu \mathrm{g} / \mathrm{kg} / \mathrm{min}$ norepinephrine vs. control group, $P<0.05 ;+0.25 \mu \mathrm{g} / \mathrm{kg} / \mathrm{min}$ phenylephrine vs. $0.05 \mu \mathrm{g} / \mathrm{kg} / \mathrm{min}$ norepinephrine group, $P<0.05$ based on ANOVA

at T5, T6, T7, T8, T9, T10 timepoint (Supplement-table-1). The CO was significantly increased at T8, $10.52 \pm 4.104$ $(P<0.0001)$, T9, $9.965 \pm 2.742(P=0.0003)$.

\section{Blood gas indices}

The UV $\mathrm{PO}_{2}$ in Phenylephrine, $30.50 \pm 6.24(P=0.0143)$ and norepinephrine, $30.62 \pm 6.91(P=0.0093)$ significantly higher and $\mathrm{SO}_{2}$ values in Phenylephrine, 64.68 \pm 13.79 $(P=0.0109)$ and norepinephrine, 64.49 $\pm 15.76 \quad(P=$ $0.0123)$ than those in the control group, $27.44 \pm 7.54$; $57.26 \pm 17.92$. However, the UV lactate level, $1.91 \pm 0.43$ in the phenylephrine group was significantly lower than those in the control, $2.30 \pm 0.84(P=0.0003)$ and norepinephrine groups $2.25 \pm 0.66(P=0.0106)$. The UV BE value showed no significant difference among the three groups. The phenylephrine group had a relatively higher UV $\mathrm{pH}$ value7.37 $\pm 0.03(P=0.0113)$ than those in the control7.36 \pm 0.04 , but the mean $\mathrm{pH}$ value in all three groups was within the normal clinical range. The UV AG value was significantly lower in the phenylephrine group-0.02 \pm 2.73 than those in the control1.49 $\pm 2.96(P=0.0005)$ and norepinephrine groups1.84 $\pm 1.72(P=0.0001)$ (Fig. 3a).
Regarding the UA parameters, there was no significant difference in the $\mathrm{PO}_{2}, \mathrm{SO}_{2}, \mathrm{PCO}_{2}, \mathrm{pH}, \mathrm{AG}$, and glucose values among the three groups. The UA lactate level in the phenylephrine group2.05 $\pm 0.61 \quad(P=0.0038)$ was significantly lower than that in the control group, $2.53 \pm 1.01$. Only the norepinephrine group showed a positive $\mathrm{UA} B E$ value $0.24 \pm 1.86$ when compared with the other two groups$0.53 \pm 1.84,-0.38 \pm 1.53(P=0.0039)(P=0.0056)$ (Fig. 3b).

Regarding the maternal PV parameters, there were no significant differences in any of the parameters among the three groups (Fig. 3c).

Comparison of adverse reactions among the three groups In the phenylephrine group, bradycardia occurred in two cases, but there was no significant difference compared with the other two groups. Administering prophylactic norepinephrine or phenylephrine infusion significantly reduced the incidence of intra-operative hypotension during CD as compared with the control group (phenylephrine vs. control group, $X^{2}$ value $=21.04, \mathrm{df}=1, P<0.0001$; norepinephrine vs. control group, $\chi^{2}$ value $=24.44, \mathrm{df}=1, \mathrm{P}<0.0001$ ). The phenylephrine group has lower Nausea incidence (phenylephrine vs. control group, $\chi^{2}$ value $=8.088, \mathrm{df}=1, P=$

Table 2 Intraoperative characteristics of the phenylephrine, norepinephrine and control group

\begin{tabular}{|c|c|c|c|c|c|}
\hline Variables & Control group $(n=78)$ & Phenylephrine group $(n=71)$ & Norepinephrine group $(n=74)$ & F value & $P$ value \\
\hline Bleeding, ml & $249.36(64.71)$ & $236.62(68.12)$ & 248.65 (78.06) & 0.9075 & 0.405 \\
\hline Urine output, ml & $214.23(76.73)$ & $211.97(68.38)$ & $214.19(84.20)$ & 0.0206 & 0.980 \\
\hline Total volume of infusion, ml & 847.09 (230.77) & $786.22(135.33)$ & 791.89 (161.97) & 2.587 & 0.078 \\
\hline Operation duration, min & $44.76(12.43)$ & $42.87(11.19)$ & $42.08(8.11)$ & 1.244 & 0.290 \\
\hline Anesthesia duration, min & $71.60(16.53)$ & $70.21(15.85)$ & $72.14(11.51)$ & 0.3249 & 0.723 \\
\hline Delivery duration, min & $5.04(2.18)$ & $5.21(2.03)$ & $5.12(1.97)$ & 0.1301 & 0.878 \\
\hline APGAR score & $9.97(0.16)$ & $10(0)$ & $9.99(0.12)$ & 0.9158 & 0.402 \\
\hline
\end{tabular}

Data are expressed as mean (SD); ${ }^{*} 0.25 \mu \mathrm{g} / \mathrm{kg} / \mathrm{min}$ phenylephrine vs. control group, $P<0.05 ; \# 0.05 \mu \mathrm{g} / \mathrm{kg} / \mathrm{min}$ norepinephrine vs. control group, $P<0.05 ;+0.25 \mu \mathrm{g} /$ $\mathrm{kg} / \mathrm{min}$ phenylephrine vs. $0.05 \mu \mathrm{g} / \mathrm{kg} / \mathrm{min}$ norepinephrine group, $P<0.05$ based on ANOVA 


\section{B Hemodynamic parameters include SV, SVR and CO in three groups.}

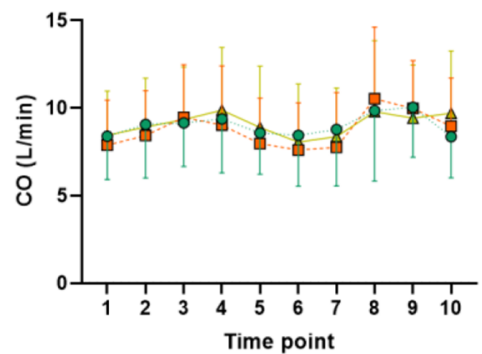

- Control Group

- phenylephrine Group

$\Delta$ Norepinephrine Group

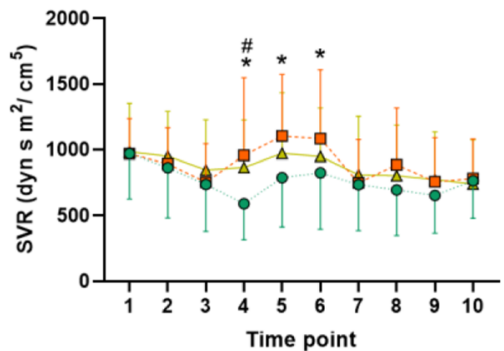

- Control Group

a. Phenylephrine Group

$\Delta$ Norepinephrine Group

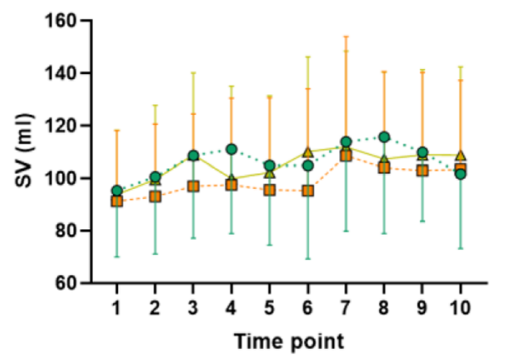

- Control Group

ㅁ. Phenylephrine Group

$\triangle$ Norepinephrine Group

A Hemodynamic parameters include SBP, DBP, MAP and HR in three groups.

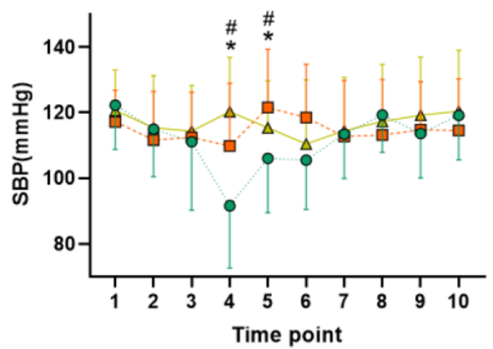

- Control group

a. phenylephrine

$\Delta$ norepinephrine

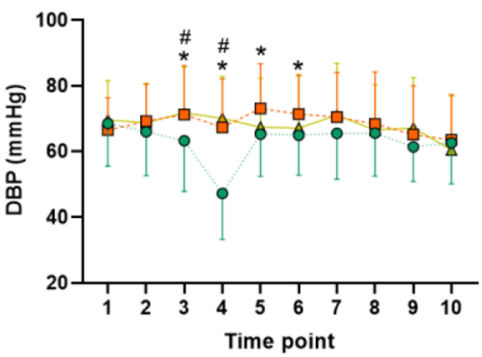

Control Group

- Phenylephrine Group

$\Delta$ Norepinephrine Group

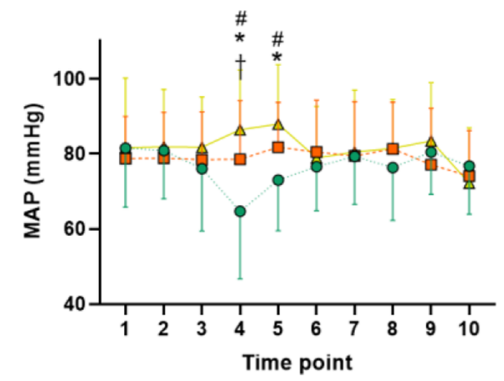

- Control Group

․ Phenylephrine Group

$\Delta$ Norepinephrine Group

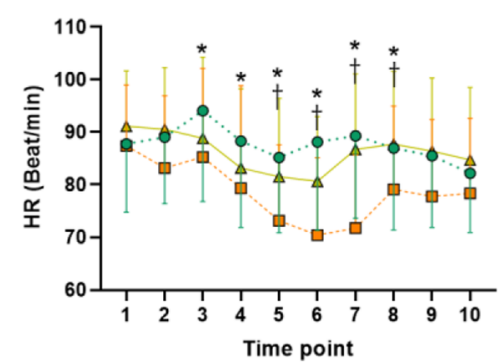

- Control Group

- Phenylephrine Group

$\Delta$ Norepinephrine Group

Fig. 2 (See legend on next page.) 
(See figure on previous page.)

Fig. 2 Hemodynamic parameters. a Stroke volume (SV), cardiac output (CO), and systemic vascular resistance (SVR) by LiDICOrapid monitoring at the 10 time points. Post hoc Bonferroni correction was performed for within- versus between-subject comparisons. Data are expressed as mean \pm standard deviation. ${ }^{*} 0.25 \mu \mathrm{g} / \mathrm{kg} / \mathrm{min}$ phenylephrine vs. control group, $P<0.05 ;{ }^{*} 0.05 \mu \mathrm{g} / \mathrm{kg} / \mathrm{min}$ norepinephrine vs. control group, $P<0.05$; $+0.25 \mu \mathrm{g} / \mathrm{kg} / \mathrm{min}$ phenylephrine vs. $0.05 \mu \mathrm{g} / \mathrm{kg} / \mathrm{min}$ norepinephrine group, $P<0.05$. b Fluctuations in heart rate (HR), systolic blood pressure (SBP), diastolic blood pressure (DBP), and mean arterial pressure (MAP) during operation at 10 time points. Markers are means, and error bars are

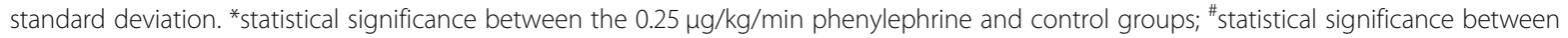
$0.05 \mu \mathrm{g} / \mathrm{kg} / \mathrm{min}$ norepinephrine group and control groups; ${ }^{\dagger}$ statistical significance between $0.25 \mu \mathrm{g} / \mathrm{kg} / \mathrm{min}$ phenylephrine and $0.05 \mu \mathrm{g} / \mathrm{kg} / \mathrm{min}$ norepinephrine groups. Post hoc Bonferroni correction was performed for within- versus between-subject comparisons

0.0045). Control group has relatively higher incidence of intra-operative tachycardia (phenylephrine vs. control group, $\chi^{2}$ value $=7.695, \mathrm{df}=1, P=0.0055$; norepinephrine vs. control group, $\chi^{2}$ value $\left.=8.011, \mathrm{df}=1, P=0.0046\right)$. When compare each group, after Bonferroni adjustment, the $P$ value $<0.0167$ indicated the significant different. There was no significant difference in the incidence of vomiting, dizziness, difficult breathing among the three groups (Table 3).

\section{Discussion}

In this study, we compared the effects of phenylephrine and norepinephrine administered as continuous infusion during elective $\mathrm{CD}$ on the maternal hemodynamic parameters and the maternal and fetal outcomes. We determined that phenylephrine and norepinephrine have similar efficacy for the prevention of SA-induced hypotension, with no difference in the incidence of maternal bradycardia. However, phenylephrine better preserved the SVR by maintaining appropriate cardiac afterload and provided better neonatal outcomes base on blood gas parameter.

In phenylephrine group, the SBP remain stable during the whole operation. In T4, T5 timepoint, decreased the SBP, DBP and MAP were observed in control group, but no significant decrease observed in phenylephrine and norepinephrine groups.

In this study, we successfully employed the LiDCOrapid system for noninvasive assessment of the macrohemodynamic parameters (CO, SV, and SVR) during phenylephrine or norepinephrine infusion in CD. The LiDCOrapid system was previously validated for use in nonpregnant and pregnant populations [15-17]. This system enables continuous assessment of the SV based on noninvasive pulse contour analysis under spontaneous breathing, which provides a reliable hemodynamic trend $[18,19]$. The typical hemodynamic response to $\mathrm{SA}$ in parturients adversely affects the SVR, a precise dynamic marker of preload responsiveness, and requires a compensatory antagonist [20]. Phenylephrine increases the SVR to counteract the SA-induced vasodilatation. In our study, the SVR in the phenylephrine group was significantly higher than that in the other two groups at T4, T5, and T6 time points.

Based on our results, both $0.25 \mu \mathrm{g} / \mathrm{kg} / \mathrm{min}$ phenylephrine and $0.05 \mu \mathrm{g} / \mathrm{kg} / \mathrm{min}$ norepinephrine infusions maintain sufficient $\mathrm{CO}$. Unlike norepinephrine, which has a weak $\beta$ - agonistic action, phenylephrine has no $\beta$-agonistic action and is expected to cause a greater decrease in HR. The decrease in HR caused by phenylephrine may affect the maternal CO. [21] In our result, the HR of phenylephrine group decreased compare with the baseline, and slightly lower than control group, but also in the clinical normal range. Even though, the $\mathrm{CO}$ maintain stable during the whole operation. The physiologic principal due to the SVR increase in phenylephrine relatively compensate the HR decrease, then maintain the CO level. In Nagankee's study, the higher dose of phenylephrine $(0.5 \mu \mathrm{g} / \mathrm{kg} / \mathrm{min})$ caused lower CO. [22] Phenylephrine negatively affects the CO in a dose-independent manner [23]. However, in this study, there was no significant decrease in the $\mathrm{CO}$ in the phenylephrine group, likely due to the appropriate dosage $(0.25 \mu \mathrm{g} / \mathrm{kg} / \mathrm{min})$ in our research chosen. The same as CO, the maternal SV also remained constant during phenylephrine infusion throughout the study period.

In the present study, phenylephrine and norepinephrine significantly increased the $\mathrm{PO}_{2}$ and $\mathrm{SO}_{2}$ values in the $\mathrm{UV}$. These parameters are known to correlate with fetal oxygenation. Stewart et al. emphasized that even with fetal compromise, there is a need to maintain fetal oxygen delivery [8]. The increase in the $\mathrm{UV} \mathrm{PO}_{2}$ and $\mathrm{SO}_{2}$ values indicates that phenylephrine and norepinephrine enable greater oxygen delivery to the fetus. The changes in the UV glucose levels noted in this study during the vasopressor infusions reflected the changes in the maternal blood glucose levels due to stress reaction. However, the norepinephrine infusion could also have exhibited the stress hormone effect, increasing the UV glucose levels [24]. In the present study, neither the UV nor the UA glucose levels varied among the three groups, which indicates that, at the appropriate dosage, both phenylephrine and norepinephrine can maintain the parturient and the fetus in a low-stress condition. Serum lactate level is the best surrogate indicator of metabolic changes in the fetus. The main finding of our study is that both phenylephrine and norepinephrine tended to decrease the UV lactate levels. The UV lactate level was the lowest in the phenylephrine group, suggesting that phenylephrine could improve the umbilical blood flow and thereby decrease the metabolic products level, further improving the fetal circulation and oxygen supply. Phenylephrine has the propensity to increase the afterload owing 
A umbilical vein blood analysis results of three groups.
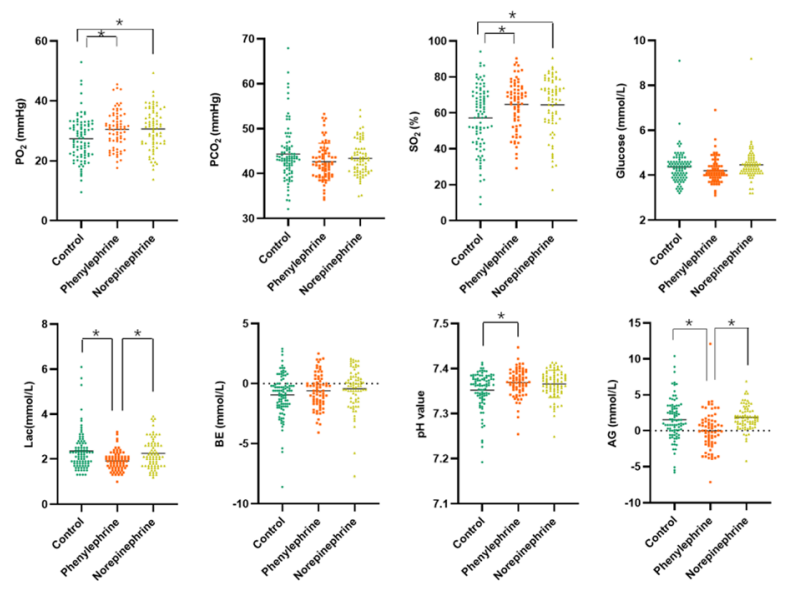

B umbilical artery blood analysis results of three groups.
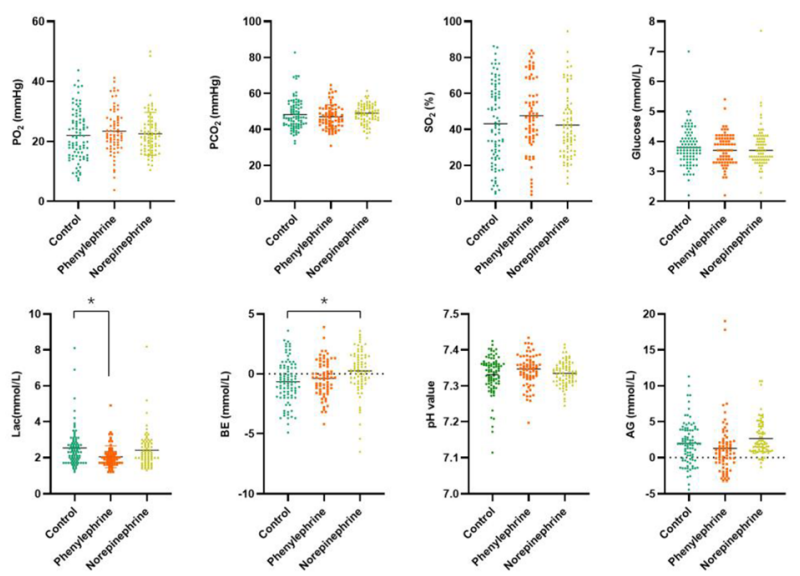

C maternal peripheral vein blood sample of three groups.
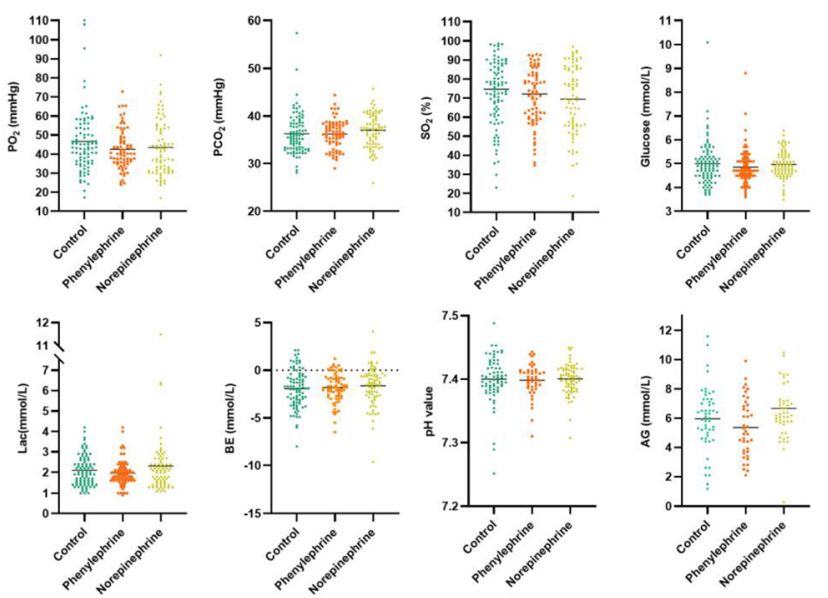

Fig. 3 Blood gas analyses. $\mathrm{PO}_{2}, \mathrm{PCO}_{2}, \mathrm{SO}_{2}$, glucose, lactate (Lac), base excess (BE), pH value, and anion gap (AG) of the (a) umbilical vein, $\mathbf{b}$ umbilical artery, $\mathbf{c}$ maternal peripheral vein blood sample of the three groups. ${ }^{*} P<0.05$ 
Table 3 Maternal outcomes in three groups

\begin{tabular}{|c|c|c|c|c|c|c|}
\hline Variables & Control group $(n=78)$ & Phenylephrine group $(n=71)$ & Norepinephrine group $(n=74)$ & $\mathrm{x}^{2}$ value & df & $P$ value \\
\hline Bradycardia (n) & $0(0)$ & $0.03(2)$ & $0.01(1)$ & 2.22 & 2 & 0.329 \\
\hline Tachycardia (n) & $0.10(8)$ & $0(0) *$ & $0(0){ }^{\#}$ & 15.43 & 2 & $<0.001$ \\
\hline Intraoperative hypotension (n) & $0.47(37)$ & $0.13(9) *$ & $0.11(8){ }^{\#}$ & 35.31 & 2 & $<0.001$ \\
\hline Nausea (n) & $0.14(11)$ & $0.01(1) *$ & $0.08(6)$ & 8.07 & 2 & 0.018 \\
\hline Vomiting (n) & $0.01(1)$ & $0(0)$ & $0.01(1)$ & 0.9 & 2 & 0.624 \\
\hline Difficulty breathing (n) & $0.12(9)$ & $0.03(2)$ & $0.03(2)$ & 7.12 & 2 & 0.028 \\
\hline Dizziness (n) & $0.08(6)$ & $0(0)$ & $0.03(2)$ & 6.61 & 2 & 0.037 \\
\hline
\end{tabular}

Data expressed as rate (number); $0.25 \mu \mathrm{g} / \mathrm{kg} / \mathrm{min}$ phenylephrine vs. control group, $P<0.05 ; \# 0.05 \mu \mathrm{g} / \mathrm{kg} / \mathrm{min}$ norepinephrine vs. control group, $P<0.05 ;+0.25 \mu \mathrm{g} /$ $\mathrm{kg} / \mathrm{min}$ phenylephrine vs. $0.05 \mu \mathrm{g} / \mathrm{kg} / \mathrm{min}$ norepinephrine group, $P<0.05$ based on chi-squared test. (after Bonnfini adjust the $P$ value $<0.0167$ has the significant different for inter-group comparison)

to its $\alpha$-antagonist action. Catecholamines do not readily cross the placental barrier [25]; hence, the UA blood gases cannot be affected by phenylephrine or norepinephrine. Changes in the UA blood gases are more likely the result of the fetal stress and fetal catecholamine level per se. Such changes affect the UA pH value. In this study, the UA pH value was better in the phenylephrine group than in the norepinephrine. Thus, infusion of low-dose phenylephrine allows for better UA $\mathrm{pH}$. In contrast, norepinephrine induces $\beta$-agonist-mediated stimulation of the fetal metabolism, leading to slight reduction in the UA pH value. Ngan Kee et al. reported no difference in the UA pH value when comparing phenylephrine with norepinephrine, which is consistent with our results. $\mathrm{BE}$ is a widely used indicator of fetal distress because higher BE values indicate better fetal acid-base status with reduced incidence of fetus acidosis. We observed higher BE values with the use of phenylephrine than those in the control or norepinephrine groups. The lower number of episodes of maternal/fetal acidosis in the phenylephrine group may reflect the positive effects of phenylephrine on the fetus.

In our study, Prophylactic norepinephrine or phenylephrine infusion effectively reduce incidence of tachycardia and intraoperation hypotension during CD. Allen et al. reported a rate of incidence of hypotension of $15 \%$ with $50 \mu \mathrm{g} / \mathrm{min}$ of phenylephrine, which is similar to our results. Nausea, occur secondary to cerebral hypoperfusion due to hypotension $[10,26]$. Numerous studies have reported reduced incidence of hypotension, intraoperative nausea, vomiting, and dizziness with prophylactic bolus of phenylephrine or norepinephrine at various doses $[8,27,28]$. In present study, nausea was lower in phenylephrine group.

A few study limitations need to be considered. We did not analyze the metabolic effect of parturients and the neonatus after delivery $24 \mathrm{~h}$ in the different vasopressor groups. Thus, although the administration of phenylephrine for prophylaxis of post-SA hypotension has shown promising results, further research is required to explore the further metabolic effect.

\section{Conclusion}

In summary, Phenylephrine, in particular, better preserves the SVR and remain appropriate blood pressure. However, the fetus outcomes are better with phenylephrine than with norepinephrine infusion, as evaluated by the decrease in the UV lactate and the increase in the UV pH value. Therefore, continuous infusion of phenylephrine at $0.25 \mu \mathrm{g} / \mathrm{kg} /$ min may improve the outcomes of parturients. These results suggested that the use of low-dose phenylephrine $(0.25 \mu \mathrm{g} / \mathrm{kg} / \mathrm{min})$ does not decrease the CO, thereby providing a better SVR and better perfusion condition of the fetus.

\section{Supplementary information}

Supplementary information accompanies this paper at https://doi.org/10. 1186/s12871-020-01145-0.

\section{Additional file 1 : Supplement Table 1. SBP. Supplement Table 2}

DBP. Supplement Table 3. MAP. Supplement Table 4. HR.

Supplement Table 5. SVR. Supplement Table 6. CO. Supplement

Table 7. SV

\section{Abbreviations}

SA: Spinal anesthesia; CD: Cesarean delivery; UV: Umbilical vein; UA: Umbilical artery; PV: Peripheral vein; SBP: Systolic blood pressure; SVR: Systemic vascular resistance; CSEA: Combined spinal-epidural anesthesia; BP: Blood pressure; HR: Heart rate; IV : Intravenous; ASA: American Society of Anesthesiologists; LR: Ringer's solution; SV: Stroke volume; CO: Cardiac output; DBP: Diastolic blood pressure; MAP: Mean arterial pressure; PO2: Oxygen partial pressure; SO2: Oxygen saturation; PCO2: Carbon dioxide partial pressure; BE: Base excess; AG: Anion gap

\section{Acknowledgements}

This research was supported by the department of obstetrics at Xuanwu Hospital.

\section{Authors' contributions}

KF; Contribution: contributed to study conduction and drafting the manuscript. XW; Contribution: contributed to data analysis and interpretation and reviewing the manuscript. XF; Contribution: contributed to anesthesia performance and record, collection the data. JZ; Contribution: contributed to blood sample collection, blood gas analysis. WX; Contribution: contributed to trial conduction and helped evaluate the patients' responses and was blinded to the medicine concentrations. FW; Contribution: contributed to trial conduction and performing the operation. QZ; Contribution: contributed to performing the operation, substantively revised the manuscript. TW; Contribution: contributed to the study design, funding, and agreed to be 
accountable for all aspects of this work. All authors read and approved the final manuscript version.

\section{Funding}

This work was supported by Beijing Municipal Health Commission (Jing2019-2), the Beijing Municipal Commission of Health and Family Planning (grant number PXM2017_026283_000002) and the Beijing Municipal Administration of Hospitals Clinical Medicine Development of Special Funding Support (grant numbers ZYLX201813, 303-01-005-0159).

\section{Availability of data and materials}

The raw data of this study are available from the corresponding author on reasonable request.

\section{Ethics approval and consent to participate}

This study was approved by the Capital Medical University Institutional Review Board on January 23, 2019 (IRB \# 2019-058). Written informed consent was obtained from all participants. The study was registered at ClinicalTrials.gov (http://clinicaltrials.gov; NCT-03833895) on February 1, 2019. Participant recruitment was performed from February 2019 to October 2019. Our methodology followed the international guidelines for randomized clinical studies according CONSORT Guidelines.

\section{Consent for publication}

Not applicable.

\section{Competing interests}

None.

\section{Author details}

'Department of Anesthesiology, Xuanwu Hospital, Capital Medical University, Beijing 100053, China. ${ }^{2}$ National Clinical Research Center for Geriatric Disorders, Beijing 100053, China. ${ }^{3}$ Department of Anesthesiology, Shanxi provincial People's Hospital, Taiyuan 030000, Shanxi, China. ${ }^{4}$ Department of Obstetrics, Xuanwu Hospital, Capital Medical University, Beijing 100053. China.

Received: 23 March 2020 Accepted: 2 September 2020

Published online: 07 September 2020

\section{References}

1. Beach M, Sites B. Vasopressors for the treatment of maternal hypotension following spinal anaesthesia for elective caesarean section: past, present and future. Anaesthesia. 2015;70:249-52.

2. Sharwood-Smith G, Drummond GB. Hypotension in obstetric spinal anaesthesia: a lesson from pre-eclampsia. Br J Anaesth. 2009;102:291-4.

3. Macarthur A, Riley ET. Obstetric anesthesia controversies: vasopressor choice for postspinal hypotension during cesarean delivery. Int Anesthesiol Clin. 2007:45:115-32

4. Reynolds F, Seed PT. Anaesthesia for caesarean section and neonatal acid base status: a meta-analysis. Anaesthesia. 2005;60:636-53.

5. Hasanin A, Aiyad A, Elsakka A, Kamel A, Fouad R, Osman M, Mokhtar A, Refaat S, Hassabelnaby Y. Leg elevation decreases the incidence of postspinal hypotension in cesarean section: a randomized controlled trial. BMC Anesthesiol. 2017;17:60.

6. Hasanin A, Soryal R, Kaddah T, Raouf SA, Abdelwahab Y, Elshafaei K, Elsayad M, Abdelhamid B, Fouad R, Mahmoud D, Hassabelnaby Y. Hemodynamic effects of lateral tilt before and after spinal anesthesia during cesarean delivery: an observational study. BMC Anesthesiol. 2018;18:8.

7. Ngan Kee WD, Khaw KS. Vasopressors in obstetrics: what should we be using? Curr Opin Anaesthesiol. 2006;19:238-43.

8. Hasanin AM, Amin SM, Agiza NA, Elsayed MK, Refaat S, Hussein HA, Rouk TI, Alrahmany M, Elsayad ME, Elshafaei KA, Refaie A. Norepinephrine infusion for preventing Postspinal anesthesia hypotension during cesarean delivery: a randomized dose-finding trial. Anesthesiology. 2019;130(1):55-62.

9. Kuhn JC, Hauge TH, Rosseland LA, Dahl V, Langesæter E. Hemodynamics of phenylephrine infusion versus lower extremity compression during spinal anesthesia for cesarean delivery: a randomized, double-blind, PlaceboControlled Study. Anesth Analg. 2016;122(4):1120-9.

10. Hirose N, Kondo Y, Maeda T, Matsui M, Matsuda M, Suzuki T. Prophylactic infusion of phenylephrine is effective in attenuating the decrease in regional cerebral blood volume and oxygenation during spinal anesthesia for cesarean section. Int J Obstet Anesth. 2019;37:36-44.

11. Cooper DW, Carpenter M, Mowbray, et al. Fetal and maternal effects of phenylephrine and ephedrine during spinal anesthesia for cesarean delivery. Anesthesiology. 2002;97:1582-90.

12. Ngan Kee WD, Lee A, Khaw KS, et al. A randomized double-blinded comparison of phenylephrine and ephedrine infusion combinations to maintain blood pressure during spinal anesthesia for cesarean delivery: the effects on fetal acid-base status and hemodynamic control. Anesth Analg. 2008;107:1295-302.

13. Xiao W, Duan QF, Zhao L, Chi XZ, Wang FY, Ma DQ, Wang TL. Goal-directed fluid therapy may improve hemodynamic stability in parturient women under combined spinal epidural anesthesia for cesarean section and newborn well-being. J Obstet Gynaecol Res. 2015;41(10):1547-55.

14. George RB, McKeen DM, Dominguez JE, Allen TK, Doyle PA, Habib AS. A randomized trial of phenylephrine infusion versus bolus dosing for nausea and vomiting during cesarean delivery in obese women. Can J Anaesth. 2018;65(3):254-62

15. Triffterer L, Marhofer P, Lechner G, Marksz TC, Kimberger O, Schmid W, Marhofer D. An observational study of the macro- and microhaemodynamic implications of epidural anaesthesia in children. Anaesthesia. 2017:72(4):488-95.

16. Nakasuji M, Okutani A, Miyata T, Imanaka N, Tanaka M, Nakasuji K, Nagai M. Disagreement between fourth generation FloTrac and LiDCOrapid measurements of cardiac output and stroke volume variation during laparoscopic colectomy. J Clin Anesth. 2016;35:150-6.

17. Asamoto M, Orii R, Otsuji M, Bougaki M, Imai Y, Yamada Y. Reliability of cardiac output measurements using LiDCOrapid ${ }^{\mathrm{TM}}$ and FloTracNigileo ${ }^{\mathrm{TM}}$ across broad ranges of cardiac output values. J Clin Monit Comput. 2017;31(4):709-16.

18. Mouchalwat ES, Bortolotto MR, et al. Use of a minimally invasive uncalibrated cardiac output monitor in patients undergoing cesarean section under spinal anesthesia: report of four cases. Rev Bras Anestesiol. 2011:61:610-8 334.

19. Dyer RA, Piercy JL, Reed AR, Strathie GW, Lombard CJ, Anthony JA, et al. Comparison between pulse waveform analysis and thermodilution cardiac output determination in patients with severe pre-eclampsia. Br J Anaesth. 2011;106:77-81.

20. Langesæter $E$, Dyer RA. Maternal haemodynamic changes during spinal anaesthesia for caesarean section. Curr Opin Anaesthesiol. 2011:24(3):242-8.

21. Stewart A, Fernando R. The dose-dependent effects of phenylephrine for elective cesarean delivery under spinal anesthesia. Anesth Analge. 2010;111:1230-7.

22. Ngan Kee WD, Lee SW, Ng FF, Tan PE, Khaw KS. Randomized doubleblinded comparison of norepinephrine and phenylephrine for maintenance of blood pressure during spinal anesthesia for cesarean delivery. Anesthesiology. 2015 Apr;122(4):736-45.

23. Ngan Kee WD, Khaw KS, Ng FF. Comparison of phenylephrine infusion regimens for maintaining maternal blood pressure during spinal anaesthesia for caesarean section. Br J Anaesth. 2004;92(4):469-74.

24. Maraaingow AG, Aford FP, Ward G. Hormonal effects of norepinephrine on acute glucose disposal in human: a minimal model analysis. Metabolism. 1988:37:885-91.

25. Puolakka J, Kauppia A. The effect of parturition on umbilical blood plasma levels of norepinephrine. Obstet Gynecol. 1983;61:19-21.

26. Habib AS. A review of the impact of phenylephrine administration on maternal hemodynamics and maternal and neonatal outcomes in women undergoing cesarean delivery under spinal anesthesia. Anesh Analg. 2012;114:377-90.

27. Loubert C, Gagnon PO, Fernando R. Minimum effective fluid volume of colloid to prevent hypotension during caesarean section under spinal anesthesia using a prophylactic phenylephrine infusion: an up-down sequential allocation study. J Clin Anesth. 2017;36:194-200.

28. Mwaura L, Mung'ayi V, Kabugi J, Mir S. A randomised controlled trial comparing weight adjusted dose versus fixed dose prophylactic phenylephrine infusion on maintaining systolic blood pressure during caesarean section under spinal anaesthesia. Afr Health Sci. 2016;16(2):399-411.

\section{Publisher's Note}

Springer Nature remains neutral with regard to jurisdictional claims in published maps and institutional affiliations. 